\title{
Triplet heterotopic pregnancy following ovulation induction with clomiphene citrate: a case report and review of literature
}

\author{
Maheswari S*, Seetha Panicker
}

Department of Obstetrics and Gynaecology, PSG Institute of Medical Sciences \& Research, Coimbatore-641004, India

Received: 24 October 2013

Accepted: 13 November 2013

\section{*Correspondence:}

Dr. Maheswari S,

E-mail: mahesprathi@gmail.com

(C) 2013 Maheswari S et al. This is an open-access article distributed under the terms of the Creative Commons Attribution Non-Commercial License, which permits unrestricted non-commercial use, distribution, and reproduction in any medium, provided the original work is properly cited.

\begin{abstract}
Heterotopic pregnancy, though rare is a combined pregnancy in which synchronous intrauterine and extra uterine pregnancy occur. An estimated incidence of between $1 / 8000$ to $1 / 30,000$ has been reported following spontaneous conception. After artificial reproductive techniques, the incidence is as high as 1/100 and after ovulation induction with clomiphene citrate, it is around 1/900. We are reporting a case of 26 year old gravida 2 who conceived after ovulation induction with clomiphene citrate and presented to the emergency department with acute abdominal pain. Ultrasound pelvis showed viable twin intrauterine gestation of 8 weeks along with ruptured ectopic pregnancy on the right tube. After stabilizing the patient, emergency laparotomy and right salpingectomy was performed. Fortunately, the intrauterine twin fetuses grew satisfactorily and patient was delivered by caesarean section at 36 weeks in view of previous lower segment caesarean section with preterm labour. Heterotopic pregnancy must be considered in a patient with amenorrhea, abdominal pain, adnexal mass and enlarged uterus particularly, conception following artificial reproductive techniques or fertility drugs, even though the intrauterine pregnancy has been documented. A high index of suspicion is important to avoid maternal morbidity, sometimes mortality and loss of intrauterine pregnancy.
\end{abstract}

Keywords: Heterotopic pregnancy, Ovulation induction

\section{INTRODUCTION}

A heterotopic pregnancy is the coexistence of simultaneous intrauterine and ectopic pregnancy. ${ }^{1-3}$ The incidence is estimated to be between $1 / 8000$ to $1 / 30,000$ following spontaneous conception. But the incidence increases following artificial reproductive techniques which is as high as $1 \% .^{1,2,4}$ Ovulation induction with clomiphene citrate increases the rate of intrauterine twinning and also is associated with heterotopic pregnancy rate of $1 / 900{ }^{6}$ Diagnosis of heterotopic pregnancy is still a challenge to the obstetrician. Diagnosing at an earlier gestational period and appropriate management is necessary to avoid loss of coexisting intrauterine pregnancy and maternal morbidity.

\section{CASE REPORT}

A 26 year old Gravida 2 Para 1 had come to our emergency department with 8 weeks amenorrhea and acute abdominal pain. Her previous delivery was a caesarean section done 3 years ago for non progression of labour. She had received clomiphene citrate for one cycle for ovulation induction following which her conception was confirmed by urine pregnancy test at 7 weeks of amenorrhea. On arrival at the emergency department, she had severe and diffuse abdominal pain, her pulse rate was 120/min and blood pressure was $80 / 40 \mathrm{~mm} \mathrm{Hg}$. She was clinically pale with $\mathrm{Hb}$ of $6.4 \mathrm{~g} / \mathrm{dl}$. Bimanual pelvic examination showed uterine size of 10 weeks, severe forniceal tenderness and no bleeding per vagina. Urgent ultrasound was ordered and it showed viable dichorionic diamniotic twin intrauterine 
gestation of $8^{+4}$ weeks and $8^{+3}$ weeks. In addition, moderate amount of free fluid in the peritoneal cavity was found and ruptured ectopic pregnancy or ruptured corpus luteal cyst was suspected. Patient was stabilized and taken up for emergency laparotomy. Around 1500ml of blood and $700 \mathrm{ml}$ of clots were removed. The site of rupture was in the ampullary portion of right tube and right sided salpingectomy was performed. Uterus was enlarged with intrauterine pregnancy and the other tube and both ovaries were normal. Care was taken to handle the uterus as little as possible. Three units of packed red cells and four units of fresh frozen plasma were transfused. Post operatively, patient had uneventful recovery. Pelvic ultrasound done before discharge confirmed the viability of both fetuses. Histopathology confirmed the diagnosis of ruptured tubal ectopic gestation. During review, nuchal translucency scan for both fetuses were within normal limits. The patient had routine regular antenatal care and the pregnancy progressed without complications till 36 weeks. As the patient had preterm pain with scar tenderness, emergency repeat caesarean section was done at 36 weeks and she delivered twin boy babies of weight 2100gms and $2000 \mathrm{gms}$. Mother and both babies are doing well now.

\section{Salient features about our case are}

1. Patient had multiple intrauterine pregnancy with tubal ectopic pregnancy following ovulation induction.

2. She had presented with features of hypovolemic shock, hence the diagnosis was considered.

3. In spite of hypovolemic shock, both fetuses survived.
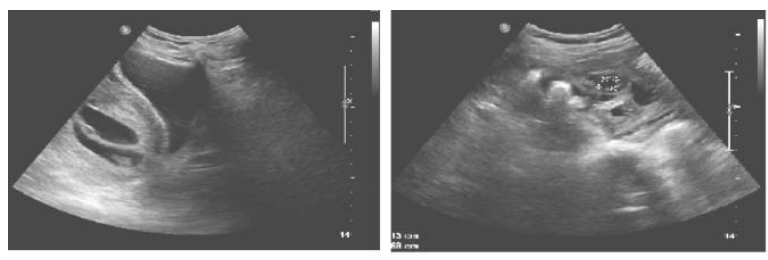

Figure 1: Ultrasound image showing multiple intra uterine pregnancy \& tubal ectopic gestational sac.

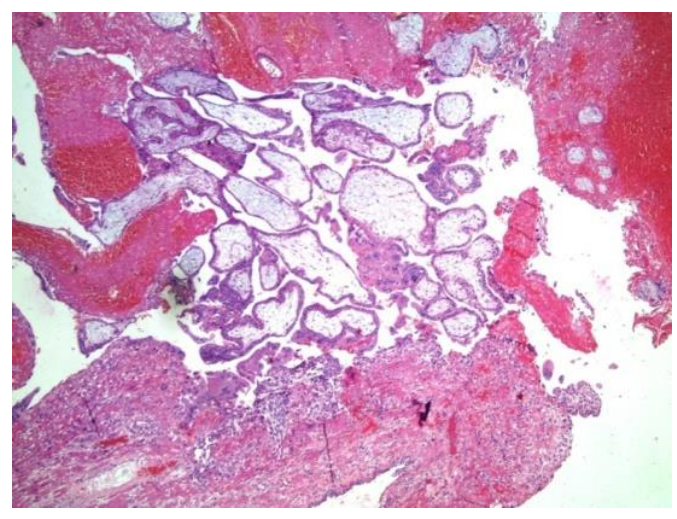

Figure 2: Histopathology image showing ruptured tubal ectopic gestation.

\section{DISCUSSION}

Today there is increase in use of artificial reproductive techniques and drugs like clomiphene citrate and gonadotropins to improve the fertility rate. This raises the patient's risk of getting a heterotopic pregnancy due to combined effect of hyperstimulation and simultaneous transfer of more than one embryo into the uterus and retrograde flow into the fallopian tubes. Raccuia et al (1989), Glassmer et al (1990), Kably Ambe et al (1995), Naki et al (2006) and many more had reported heterotopic pregnancies following ovulation induction with clomiphene citrate. ${ }^{12,16,17,18}$

- Other factors which are responsible for infertility like pelvic inflammatory disease, previous tubal surgeries also contribute to heterotopic pregnancy. $3,7,8,9$

- In our patient also, right tubal ectopic along with twin intrauterine pregnancy has occurred following use of clomiphene citrate for ovulation induction. Payne et al (1971) reported a case of ectopic pregnancy concomitant with twin intrauterine pregnancy. ${ }^{13}$

- Dietz et al (1993) reported a case of combined bilateral tubal ectopic with multiple intrauterine pregnancy after ovulation induction. ${ }^{14}$.

- Diagnosing heterotopic pregnancy is still a challenge for the obstetrician. Around $50 \%$ of cases are asymptomatic ${ }^{10}$ and diagnosed very late. Due to the presence of the intrauterine gestational sac, ectopic pregnancy is not considered. Significant morbidity, sometimes mortality have been reported as a result of delay in diagnosis ${ }^{3}$. When symptomatic, the features are abdominal pain due to peritoneal irritation, adnexal mass with or without vaginal bleeding and hypovolemic shock.

- Estimation of human chorionic gonadotrophin is unreliable as there is a coexisting intrauterine pregnancy. Likewise, abdominal and pelvic ultrasound also fails to demonstrate the ectopic component or is misinterpreted because of the presence of existing intrauterine pregnancy., 3

- As no single investigation can predict the coexisting heterotopic pregnancy, it should be suspected when a pregnant mother in her earlier weeks of gestation presents with lower abdominal pain even with a documented intrauterine pregnancy. This is particularly important following fertility treatment. ${ }^{7,11}$ Demonstration of an intrauterine pregnancy either viable or not, is no longer a reliable indicator for excluding an ectopic pregnancy. 3,5

For an unruptured ectopic pregnancy, systemic methotrexate is contraindicated because of viable intrauterine pregnancy. Local instillation of $\mathrm{KCl}$ or hyperosmolar glucose into the unruptured sac can be tried. $^{9}$ Nowadays, laparoscopic salpingostomy or 
salpingectomy is preferred over laparotomy to minimize manipulation of the pregnant uterus. ${ }^{7}$ Gruber et al (2002) reported 3 cases of heterotopic pregnancy, of them 2 were following artificial reproductive techniques, 1 was following tubal surgery for previous ectopic pregnancy. All 3 underwent laparoscopic salpingectomy, of them 1 had twin intrauterine pregnancy who delivered at 37 weeks by elective caesarean section. ${ }^{15}$

For the ruptured ectopic, laparoscopic surgery is an option if the patient is hemodynamically stable. If the hemodynamic status is compromised, emergency laparotomy is the only choice.

\section{CONCLUSION}

Clinicians should have a high index of suspicion of heterotopic pregnancy in patients presenting with amenorrhea, abdominal pain, adnexal mass and enlarged uterus, though intrauterine pregnancy has been confirmed. With early diagnosis and appropriate treatment, $70 \%$ of intrauterine pregnancy will reach viability. ${ }^{19}$

It is recommended that even patients shown on ultrasound to have intrauterine pregnancy should be given comprehensive pelvic ultrasound so that possibility of synchronous heterotopic pregnancy can be excluded, particularly in pregnancies following fertility treatment.

\section{REFERENCES}

1. Dumesic DA, Damario MA, Session DR: Interstitial heterotopic pregnancy in a women conceiving by invitro fertilization after bilateral salpingectomy. Mayo clin Proc 2001, 76:90-92.

2. Maalt ME, Murad Nand Dabbas M: Advanced heterotopic pregnancy. J obstet gynaecol 1999, 19:677-678.

3. Mistry BM, Balasubramaniam S, Silverman R, Sakabu SA, Troop BR: Heterotopic pregnancy presenting as an acute abdomen: A diagnostic masquerader. Am Surg 2000, 66(3):307-308.

4. Dessole S, Ruiu GA, Cherichi PL: Coexistene of a heterotopic pregnancy associated with a homolateral ovarian cyst in a patient subjected to elective abortion. Gynecol Obstet Invest 2000;49:277-278.
5. Hill J: Assisted reproduction and the multiple pregnancy: Increasing the risks for heterotopic pregnancy. J Diagn Med Sonogr 2003, 19:258-260.

6. Bello G, Schonholz D, Moshirpur J, Jeng DY, Berkowitz RL: Combined pregnancy: The mount Sinai experience. Obstet Gynecol Surv 1986, 41:603-613.

7. Perkins JD, Mitchell MR: Heterotopic pregnancy in a large inner city hospital: A report of 2 cases. J Natl Med Assoc 2004, 96:363-366.

8. Mishra A, Youssefzadeh D, Parente JT. Heterotopic pregnancy. Female patient 1998;23:39-42.

9. Scheiber MD, Cedars MI. Succesful non surgical management of a heterotopic pregnancy of an abdominal pregnancy following embryo transfer with cryo preserved-thawed embryos. Hum Reprod 1999, 14:1375-1377.

10. C. Louis-Sylvestre, $P$ Morice, C Chapron and JB Dubuisson. "The role of laparoscopy in the diagnosis and management of heterotopic pregnancies", Human Reproduction, Vol.12, no 5, pp 1100-1102, 1997.

11. Arcibong EI, Etuk SJ. Case report, heterotopic pregnancy following induction of ovulation. Trop J Obstet Gynecol 2002, 19:115-116.

12. Naki MM, Tekcan C, Uysal A, Guzin K, Yucel N. Arch Gynecol Obstet 2006 Jun;274(3):181-3.

13. Payne S, Duqe J, Bradbury W, Obstet Gynecol 1971 Dec; 38(6):905-6.

14. Dietz TU, Haenggi W, Birkhaeuser M, Gyr T, Dreher E, J Obstet Gynecol Reprod Biol. 1993 Jan;48(1):69-71.

15. Gruber I, Lahodny J, Illmensee K, Losch A: Wien Klin Wochenschr. 2002 Mar 28;114(5-6):229-32.

16. Raccuia JS, Neckles S, Butler D, Kahn M, Ibrahim IM. Surg Gynecol Obstet. 1989 May;168(5):417-20.

17. Glassner MJ, Aron E, Eskin BA. J Reprod Med $1990 \mathrm{Feb} ; 35(2): 175-8$.

18. Kably Ambe A, Werner von der Medan Alarcon J, Garcia Leon JF, Reyes Cuervo H. Ginecol Obstet Mex. 1995 Aug;63:346-8.

19. Nguyen-Tran C, Toy EC. Heterotopic pregnancy: Viable twin intrauterine pregnancy with a viable right tubal ectopic pregnancy. Journal of Ultrasound in Medicine 2000;19(5):article 355.

DOI: 10.5455/2320-1770.ijrcog20131260

Cite this article as: Maheswari S, Panicker S.

Triplet heterotopic pregnancy following ovulation induction with clomiphene citrate: a case report and review of literature. Int J Reprod Contracept Obstet Gynecol 2013;2:743-5. 